\title{
Broadband Shock Noise in Internally-Mixed Dual-Stream Jets
}

James E. Bridges

Glenn Research Center, Cleveland, Ohio 


\section{NASA STI Program . . . in Profile}

Since its founding, NASA has been dedicated to the advancement of aeronautics and space science. The NASA Scientific and Technical Information (STI) program plays a key part in helping NASA maintain this important role.

The NASA STI Program operates under the auspices of the Agency Chief Information Officer. It collects, organizes, provides for archiving, and disseminates NASA's STI. The NASA STI program provides access to the NASA Aeronautics and Space Database and its public interface, the NASA Technical Reports Server, thus providing one of the largest collections of aeronautical and space science STI in the world. Results are published in both non-NASA channels and by NASA in the NASA STI Report Series, which includes the following report types:

- TECHNICAL PUBLICATION. Reports of completed research or a major significant phase of research that present the results of NASA programs and include extensive data or theoretical analysis. Includes compilations of significant scientific and technical data and information deemed to be of continuing reference value. NASA counterpart of peer-reviewed formal professional papers but has less stringent limitations on manuscript length and extent of graphic presentations.

- TECHNICAL MEMORANDUM. Scientific and technical findings that are preliminary or of specialized interest, e.g., quick release reports, working papers, and bibliographies that contain minimal annotation. Does not contain extensive analysis.

- CONTRACTOR REPORT. Scientific and technical findings by NASA-sponsored contractors and grantees.
- CONFERENCE PUBLICATION. Collected papers from scientific and technical conferences, symposia, seminars, or other meetings sponsored or cosponsored by NASA.

- SPECIAL PUBLICATION. Scientific, technical, or historical information from NASA programs, projects, and missions, often concerned with subjects having substantial public interest.

- TECHNICAL TRANSLATION. Englishlanguage translations of foreign scientific and technical material pertinent to NASA's mission.

Specialized services also include creating custom thesauri, building customized databases, organizing and publishing research results.

For more information about the NASA STI program, see the following:

- Access the NASA STI program home page at http://www.sti.nasa.gov

- E-mail your question via the Internet to help@ sti.nasa.gov

- Fax your question to the NASA STI Help Desk at $443-757-5803$

- Telephone the NASA STI Help Desk at 443-757-5802

- Write to: NASA Center for AeroSpace Information (CASI) 7115 Standard Drive Hanover, MD 21076-1320 


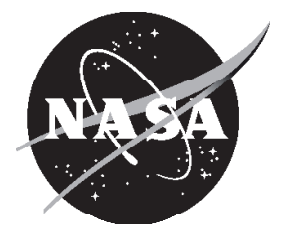

\section{Broadband Shock Noise in Internally-Mixed Dual-Stream Jets}

James E. Bridges

Glenn Research Center, Cleveland, Ohio

Prepared for the

15th Aeroacoustics Conference (30th AIAA Aeroacoustics Conference) cosponsored by AIAA and CEAS

Miami, Florida, May 11-13, 2009

National Aeronautics and

Space Administration

Glenn Research Center

Cleveland, Ohio 44135 
Trade names and trademarks are used in this report for identification only. Their usage does not constitute an official endorsement, either expressed or implied, by the National Aeronautics and Space Administration.

This work was sponsored by the Fundamental Aeronautics Program at the NASA Glenn Research Center.

Level of Review: This material has been technically reviewed by technical management.

Available from

NASA Center for Aerospace Information 7115 Standard Drive

Hanover, MD 21076-1320
National Technical Information Service 5285 Port Royal Road Springfield, VA 22161

Available electronically at http://gltrs.grc.nasa.gov 


\title{
Broadband Shock Noise in Internally-Mixed Dual-Stream Jets
}

\author{
James E. Bridges \\ National Aeronautics and Space Administration \\ Glenn Research Center \\ Cleveland, Ohio 44135
}

\begin{abstract}
Broadband shock noise (BBSN) has been studied in some detail in single-flow jets and recently in dual-stream jets with separate flow exhaust systems. Shock noise is of great concern in these latter cases because of the noise created for the aircraft cabin by the underexpanded nozzle flow at cruise. Another case where shock noise is of concern is in the case of future supersonic aircraft that are expected to have bypass ratios small enough to justify internally mixed exhaust systems, and whose mission will push cycles to the point of imperfectly expanded flows. Dual-stream jets with internally mixed plume have some simplifying aspects relative to the separate flow jets, having a single shock structure given by the common nozzle pressure. This is used to separate the contribution of the turbulent shear layer to the broadband shock noise. Shock structure is held constant while the geometry and strength of the inner and merged shear layers are varying by changing splitter area ratio and core stream temperature. Flow and noise measurements are presented which document the efforts at separating the contribution of the inner shear layer to the broadband shock noise.
\end{abstract}

\section{Introduction}

For many years researchers have compared convergent-divergent and convergent nozzles to isolate broadband shock noise (BBSN), under the assumption that BBSN is independent of jet mixing noise (Refs. 1 and 2). That seems consistent with observations that low frequency noise at aft angles stays the same. The physical mechanism of BBSN seems well understood in that it involves the interaction of the standing pattern of flow inhomogeneities (shocks) with convecting turbulence. The shock strengths and spacings are largely given by the fully expanded Mach number $M$. The strength and spectral content of the turbulence in the shear layer is given by velocity gradient, $\partial U / \partial$ r. Further, Tam's wavy wall analogy which successfully predicts the frequency shift of the peak BBSN, implicates the convection speed of the turbulence as having a major role in the source mechanism of BBSN. Consequently, BBSN is a function of Mach number $M$ and jet velocity $U$. Conventionally, BBSN has been assumed to be independent of jet temperature (Ref. 1), although recent papers have found some dependence (Ref. 2). Whether this is sensitivity to temperature or to shear velocity is not possible to ascertain since the two are tied for a given Mach number $M$.

Real engines have two streams of gas, sometimes issuing through a common nozzle with varying degrees of mixing between streams. Given that the two streams share the common plenum just upstream of the nozzle exit, they have the same total pressure, but differ in temperature and therefore in velocity. Having a common pressure results in a shock cell pattern that differs little from that of a single-stream jet of the same $M$. The strength of the outer shear layer is given by the gradient of velocity, in this case initially of the bypass stream velocity $U_{b}$, and the outer flight stream. The internal shear layer, however, presents a second source of turbulence convected through the standing shock pattern, and would seem likely to be a second source of BBSN. The strength and spectral character of this turbulence is given by the velocity ratio between the streams, $U_{b} / U_{c}$, and the geometry of the splitter. Here, BBSN is expected to be a function of the common Mach number $M$, the core velocity $U_{c}$, the bypass velocity $U_{b}$, and splitter area ratio. Further downstream after the core and bypass streams merge the core stream contributes to the outer shear layer strength, a complicated process that also strongly depends on the splitter area ratio. 
To separate the impact of the internal shear layer on the BBSN source and to provide a database of practical jet mixing noise cases, a series of experiments were performed with internally mixed, dualstream jets. Besides varying the nozzle divergence to create plume shocks or not, the exhaust system had different fan-core area ratios, and hence different bypass ratios, while varying the volume of the internal shear layer. Finally, these exhaust systems were run over a range of core temperature ratios to vary the core velocity $U_{c}$ while holding bypass velocity $U_{b}$ constant, and hence varying the strength of the internal shear layer.

The experiments were set up following the understanding of broadband shock noise put forth by Tam in Reference 3, among other references. The findings in general do not contradict most insights proferred by these references, but do show some interesting differences brought on by the presence of the secondary stream, that complicate the generation of broadband shock. Note that the current experiments were for internally mixed exhaust systems and were different from externally mixed nozzle systems, complicated by the presence of two shock systems.

\section{Facility, Model Hardware, Instrumentation, and Flow Conditions}

The test was conducted in the NASA Glenn Research Center AeroAcoustic Propulsion Laboratory (AAPL). The AAPL is a 65-foot radius anechoic geodesic hemispherical dome. Acoustic wedges covered the walls of the dome and the floor area of the test arena. The ambient temperature, pressure, and relative humidity were recorded within the dome.

The Nozzle Acoustic Test Rig (NATR) is a large, ejector-driven freejet used to generate forward flight airflow through its 53 in. $(1.35 \mathrm{~m})$ exit. Simulated flight speeds up to Mach 0.35 were produced through the acoustically lined tunnel.

The High Flow Jet Exit Rig (HFJER) was positioned at the end of the NATR, with the nozzle exit roughly 60 in. $(1.5 \mathrm{~m})$ downstream of the NATR exit plane. The HFJER delivered high pressure air from the Center's compressed air system to the test article. Flow rates up to $25 \mathrm{lbm} / \mathrm{sec}$ are available in each of two streams. One of the streams passes through a natural gas-fired combustor that could heat the flow to approximately $1800^{\circ} \mathrm{R}$. The rig is well-instrumented with 40-element charging station rakes in both core and bypass streams. The control system allows instantaneous calculation of total pressure ratio and total temperature ratio of both streams along with the deviation from the researcher-input conditions. In this way the flow conditions were held to keep jet velocities within 0.5 percent of the intended condition, including the simulated flight stream.

The test nozzles were attached to the aft end of the HFJER and are shown in Figure 1. The model system consisted of an interchangeable set of four axisymmetric splitters and four nozzles, all of exit diameter 4 in. $(101.6 \mathrm{~mm})$. The axisymmetric splitters yielded area ratios of $0.2,1.0,2.0$, and 3.0. The convergent-divergent nozzles were designed using the method of characteristics and tuned with RANS CFD to produce nearly perfectly expanded flows of Mach 1.18 (M2), 1.4 (M4), and 1.5 (M5). The convergent nozzle, designated $\mathrm{C} 4$, was modified in the middle of testing to accommodate a set of eight tabs with adjustable penetration as shown in the figure. A center plug, required to achieve the highest bypass ratio, was varied in length (PE1, PE2) and found to be inconsequential to the sound produced by the nozzles.

This report will cover both far-field acoustic spectral directivity and plume measurements using rakes of static pressure probes and total temperature probes. Acoustic measurements were recorded by an array of 24 microphones placed on an arc with a radius of $45 \mathrm{ft}(13.7 \mathrm{~m})$ at $5^{\circ}$ intervals from $45^{\circ}$ to $160^{\circ}$. The microphones were 1/4 in. Bruel \& Kjaer model 3949 free-field type, pointed at the nozzle exit with the grid caps removed. Bruel \& Kjaer Nexus amplifiers provide the signal conditionings. Eight seconds of data are recorded at each point on a DataMAX Instrumentation Recorder at $200 \mathrm{kHz}$ sample rate using a $90 \mathrm{kHz}$ low-pass filter to limit the bandwidth. After being corrected for amplifier gain, the prerecorded background sound levels were removed spectrally and actuator and free-field responses from the calibration facility were applied. Atmospheric attenuation was added back to the sound spectra using the formula of Shields and Bass (Ref. 4). In cases of simulated forward flight the refraction of the sound 


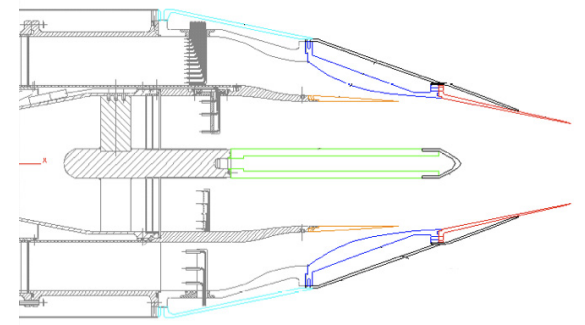

C4-S1-PE1

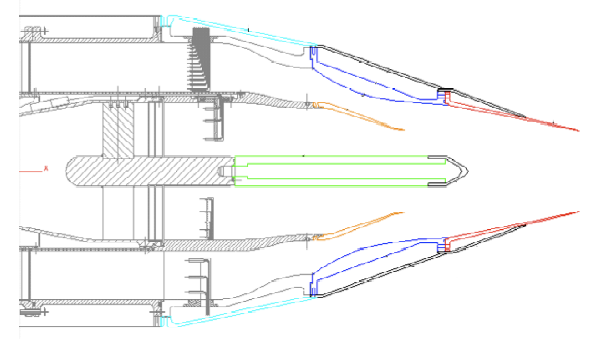

C4-S4-PE1

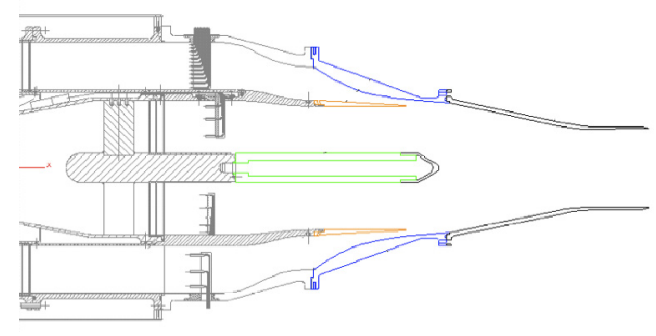

M2-S2-PE2

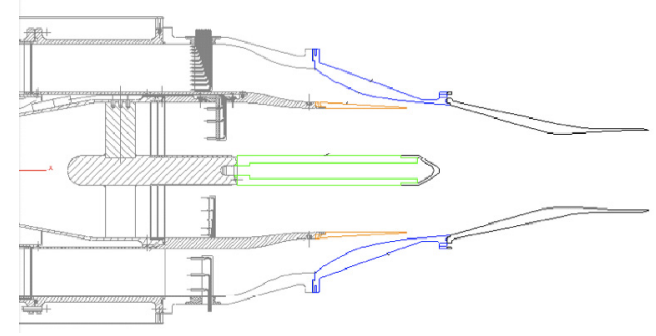

M5-S2-PE2

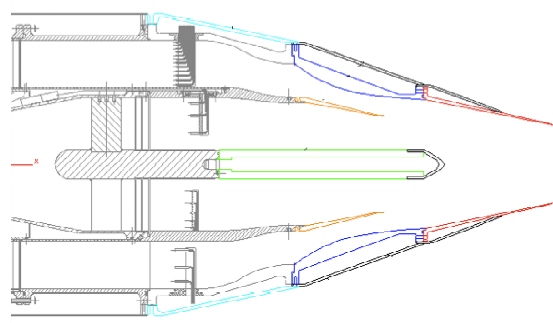

C4-S2-PE1

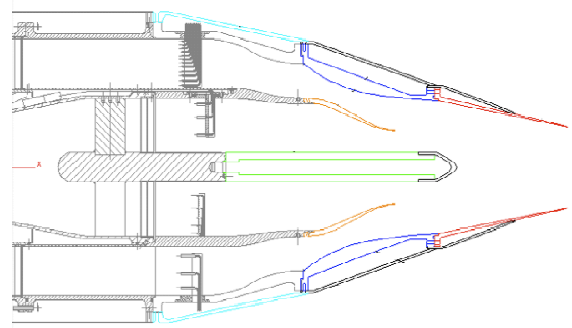

C4-S3-PE1

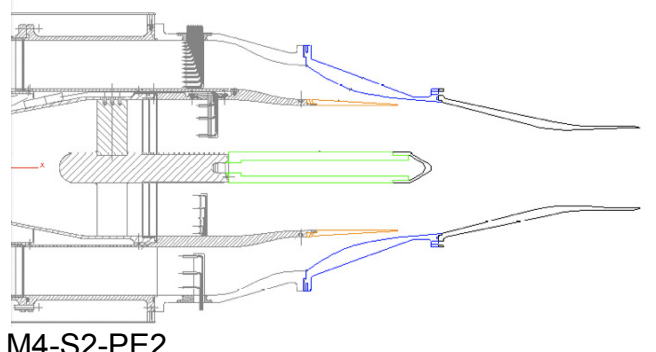

M4-S2-PE2

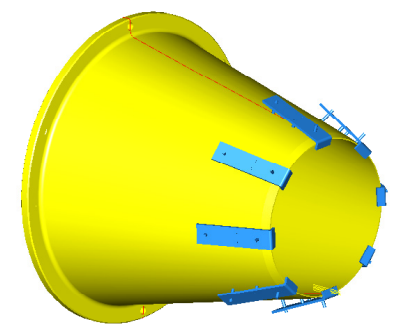

C4.5-SX-PE1

Figure 1.-Nozzles used in Supersonic Aeroacoustic Database.

through the freejet shear layer was removed and the data were transformed to a consistent 100 jet diameter distance assuming lossless spherical spreading, and interpolated to a consistent set of observer angles. The narrowband power spectral densities were further normalized using jet diameter and ideally expanded, fully mixed velocity to be presented as power spectral density as a function of Strouhal number.

The total and static pressures, and total temperature were mapped using rakes with $1 / 4 \mathrm{in}$. spacing between elements on four rakes. All probes were designed for supersonic flow. Each measurement was an average over $2 \mathrm{sec}$ of stationary probe positioning.

A series of flow conditions were defined that matched the design Mach numbers of the convergentdivergent nozzles while varying the temperature of the core to hit a common set of velocity ratios. (Even in the case of convergent nozzle flows, the fully expanded Mach number will be used.) In doing this the shock structure and turbulence intensities were to be independently varied. For this report a subset of these flow conditions are used and are documented in Table 1. The bulk of the testing was done at static 
conditions; for a few flow conditions, simulated forward flight speeds of $M_{\text {flight }}=0.2$ and 0.35 were added to the matrix. Actual test conditions were specified in terms of nozzle pressure ratio (NPR) and total temperature ratio (NTR) relative to ambient on both bypass and core streams.

\begin{tabular}{|c|c|c|c|c|c|c|}
\hline \multicolumn{1}{|c|}{ TABLE 1.-MATRIX OF FLOW CONDITIONS TESTED } \\
\hline Setpoint & $\begin{array}{c}\text { NPRc } \\
\text { Pt/Pamb }\end{array}$ & $\begin{array}{c}\text { NPRb } \\
\text { Pt/Pamb }\end{array}$ & $\begin{array}{c}\text { NTRc } \\
\text { Tt/Tamb }\end{array}$ & $\begin{array}{c}\text { NTRb } \\
\text { Tt/Tamb }\end{array}$ & Mach & $U_{b} / U_{c}$ \\
\hline 08010 & 2.425 & 2.425 & 1.0 & 1.0 & 1.19 & 1.00 \\
08050 & 2.425 & 2.425 & 2.294 & 1.0 & 1.19 & 0.66 \\
08060 & 2.398 & 2.425 & 2.912 & 1.0 & 1.19 & 0.60 \\
09010 & 3.157 & 3.157 & 1.0 & 1.0 & 1.40 & 1.00 \\
09060 & 3.130 & 3.157 & 2.397 & 1.0 & 1.40 & 0.60 \\
10010 & 3.671 & 3.671 & 1.0 & 1.0 & 1.50 & 1.00 \\
10030 & 3.670 & 3.671 & 1.328 & 1.0 & 1.50 & 0.83 \\
10050 & 3.664 & 3.671 & 2.088 & 1.0 & 1.50 & 0.69 \\
10060 & 3.652 & 3.671 & 2.361 & 1.0 & 1.50 & 0.62 \\
\hline
\end{tabular}

\section{Results}

\section{Separation of BBSN From Jet Mixing Noise Using C-D Nozzles}

As shown by many others before, broadband shock noise has a distinctive spatial directivity as well as a frequency signature denoted by an abrupt rise in noise with increasing frequency. Also, broadband shock noise appears to be independent of jet mixing noise as evidenced by the fact that when jets of the same ideally expanded velocity, one with shocks (but no screech) and one with little-to-no shock cells are coplotted, they overlap very well in the low frequencies. For example, Figure 2 shows noise spectra acquired in supersonic jets issuing from three different types of nozzles: convergent (C4S1), convergent with tabs (C4.5S1), and ideally expanded (M4S1). In this case the flow was uniform, unheated flow at $M=1.4$, the design Mach number for the convergent-divergent nozzle. The first plot, acquired at right angles to the jet, shows the recognizable jet mixing noise produced by the jet of the ideally expanded nozzle. Without tabs, the convergent nozzle produced a resonant flow with dominant tones (screech), elevated jet mixing noise at low frequencies, and broadband shock noise (BBSN) that arose above the jet mixing noise at this angle starting around $\mathrm{St} \sim 0.4$. With tabs lightly penetrating the flow at the convergent nozzle lip the screech was disrupted. The jet mixing noise was then found to exactly match that of the ideally expanded flow, leading to the conclusion that the screech caused enhancement of the jet mixing process (a conclusion supported by PIV measurements of the turbulence of shocked jets with and without screech (Ref. 5)). The BBSN, while modified by the tabs and absence of screech, was not as dramatically altered. The onset frequency was slightly increased, but the high frequency roll off was exactly the same as the screeching jet. This behavior was the same at other angles, such as $120^{\circ}$, shown in the second plot of the figure.

With sufficient heating, the conditions for resonance (screech) decreased until a screech-free jet occurred in the simple convergent nozzle. When that happened the tabs were found to have no impact on the noise field of the convergent nozzle jet flow. Figure 3 shows noise spectra in the same format as Figure 2, the only difference being that the nozzle was being fed a flow in which the core stream, comprising 80 percent of the mass, was heated to a temperature ratio of 2.4. Because of the elevated temperature, the jet velocity was raised and the jet mixing noise was enhanced. The BBSN was clearly delineated at broadside angles (e.g., $90^{\circ}$, the first plot in the figure), but was dominated by the jet mixing noise at downstream angles (e.g., $120^{\circ}$, the second plot). Furthermore, the low frequency jet mixing noise was the same for all three nozzles. With the absence of screech the shock-free and shock-containing (both plain and tabbed) jets made the same mixing noise. Evidently the very small protrusions of the tabbed jet were not sufficient to modify the jet mixing. 

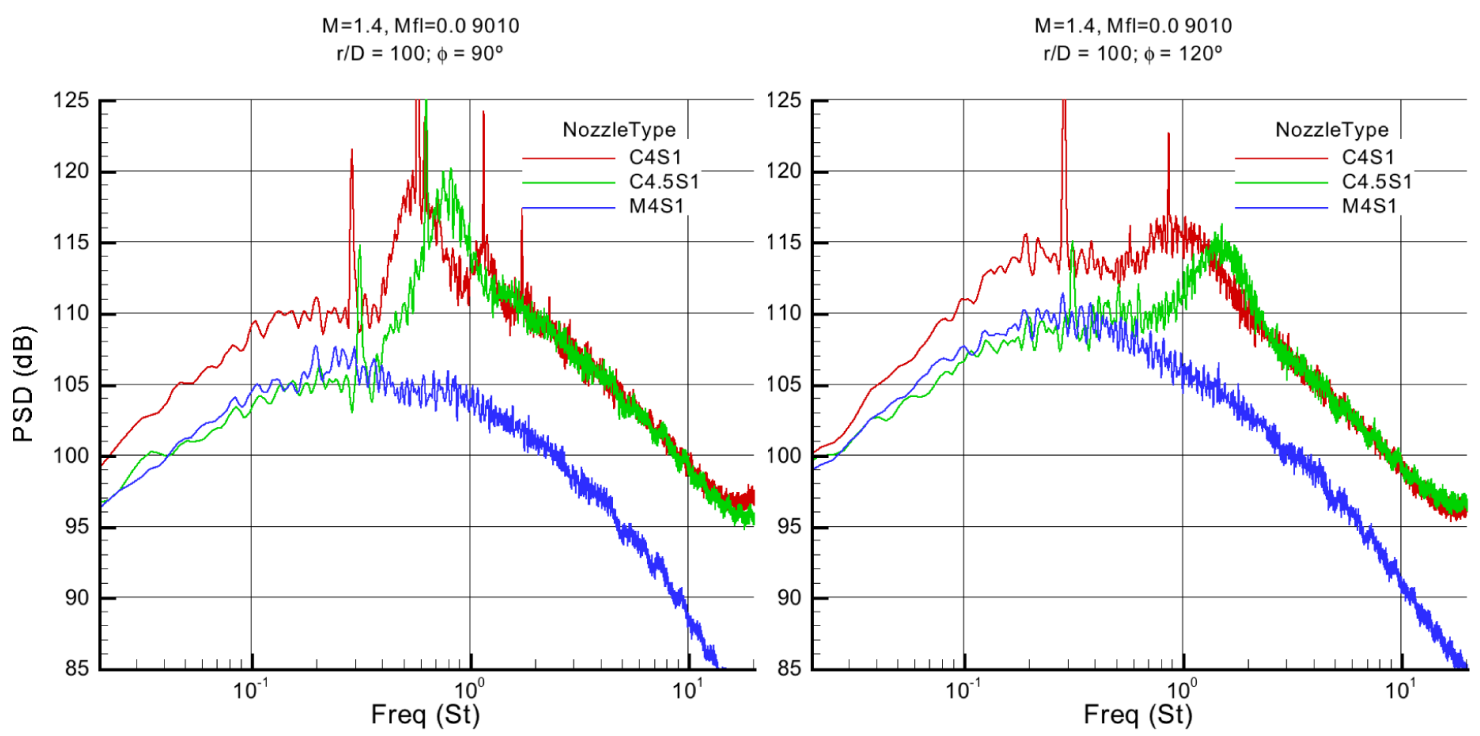

Figure 2.-Power Spectral Density of supersonic jet noise at $90^{\circ}$ (left) and $120^{\circ}$ (right) for $M=1.4$ at velocity ratio $U_{b} / U_{c}=1.0$. Curves in each plot come from different nozzle geometries (convergent, convergent with tabs, ideally expanded).
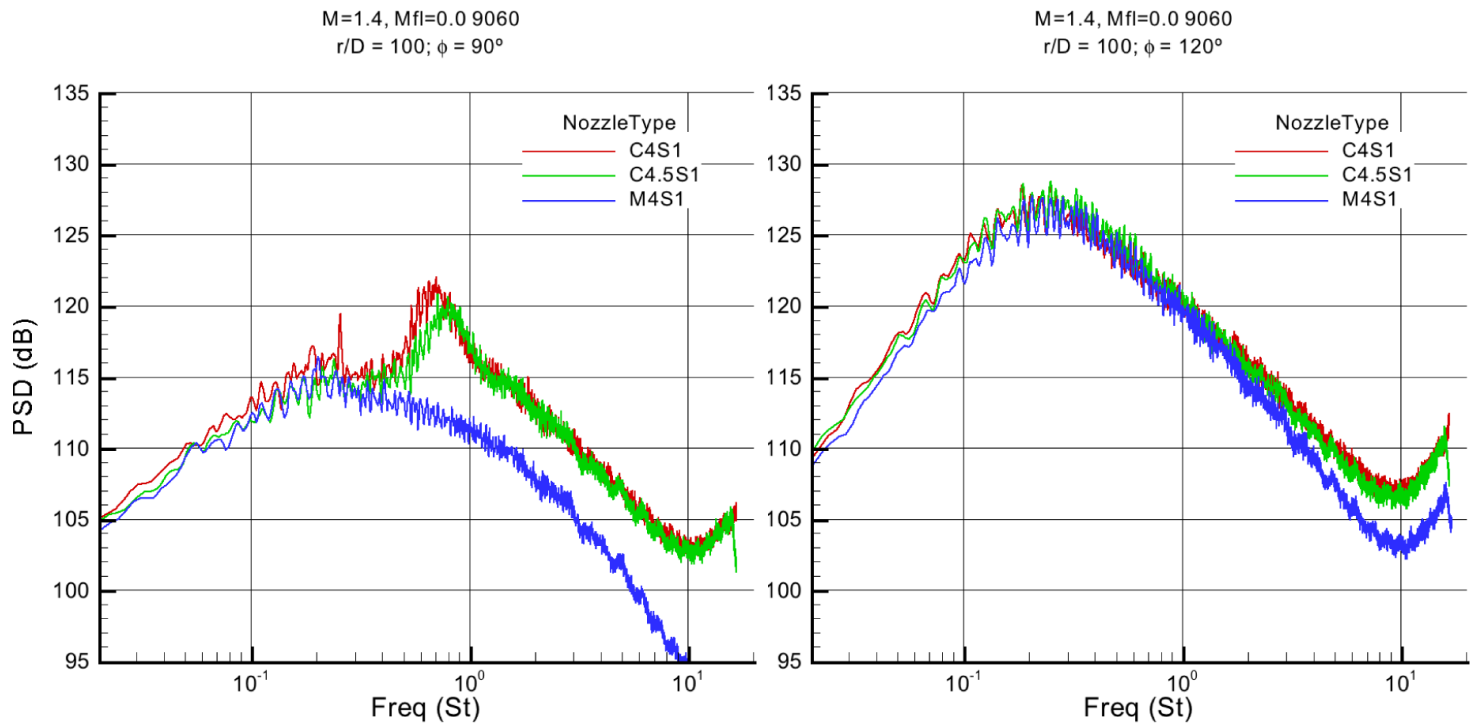

Figure 3.-Power Spectral Density of supersonic jet noise at $90^{\circ}$ (left) and $120^{\circ}$ (right) for $M=1.4$ at velocity ratio $U_{b} / U_{c}=0.83$. Curves in each plot come from different nozzle geometries (convergent, convergent with tabs, ideally expanded). 


\section{Impact of $M$, Splitter Area Ratio, and $M_{\text {flight }}$ on Plume Structure}

Plume surveys were performed on several of the jet flows with the convergent nozzle exhaust system. A few sample datasets are presented in Figure 4 that show the general trends observed:

- The shock pattern, as seen in the static pressure measurements, had strong shocks of the same pattern as expected for a single-stream jet at the same Mach number.

- The shock cell patterns were relatively independent of splitter area ratio.

- The potential cores of the jets were strongly altered by the change in splitter area ratio as seen in the temperature plots.

The introduction of forward flight only slightly modified the shock structure, as seen in Figure 5 . This figure shows two plots of static pressure, acquired for the same jet flow of $M=1.2, U_{b} / U_{c}=0.60$, but with flight stream Mach numbers of 0.0 and 0.2. Although some slight modification (a slight stretching of the shock train and quicker decay of shock strength in downstream distance) can be discerned, the change is very small. These results agree with those found in single-stream jets (Ref. 6), with the possible exception that the small reduction in shock amplitude with flight speed was not noted in the single-stream jets.
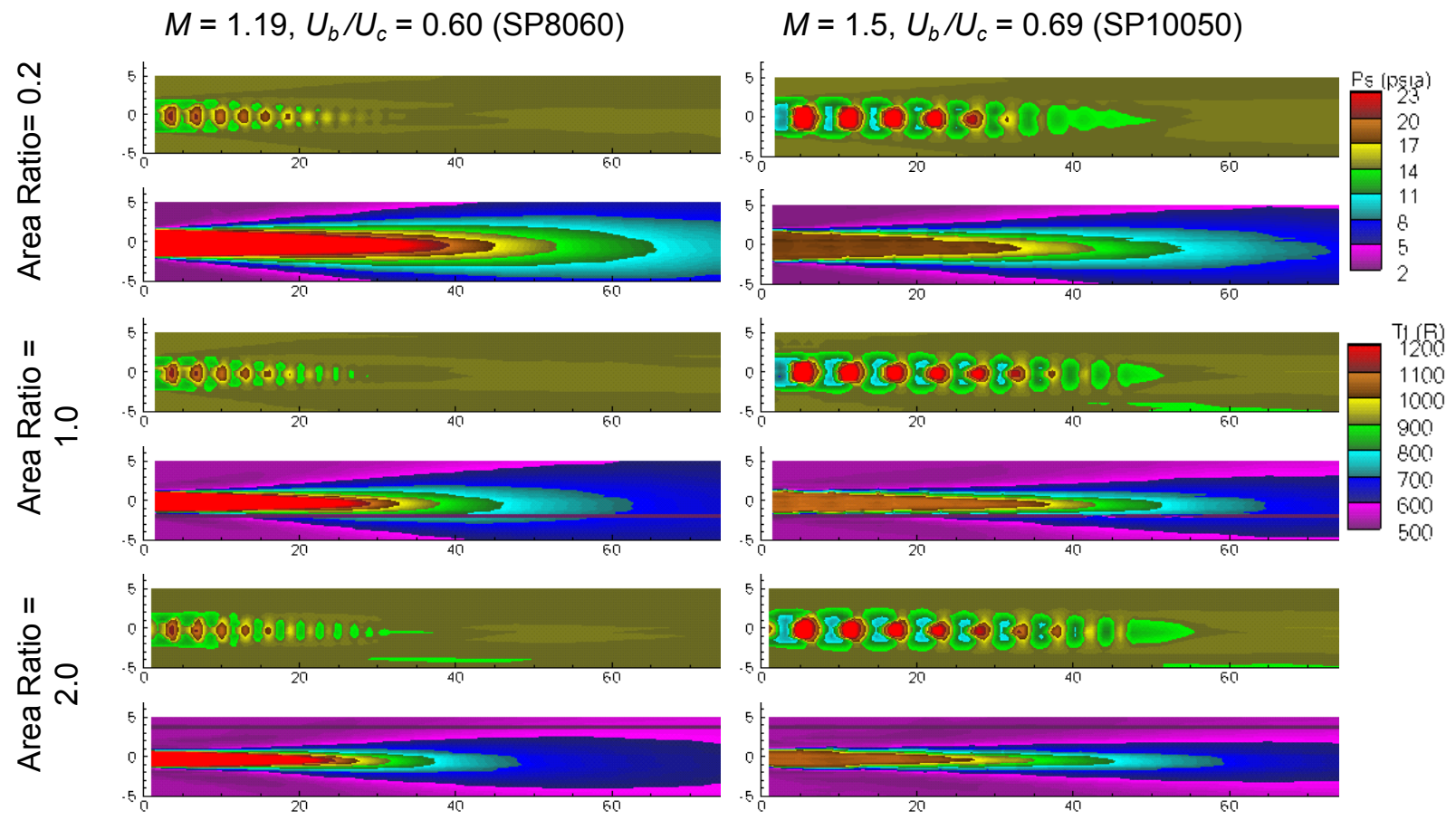

Figure 4.-Plots of Pstat (top), Ttot (bottom) for two Mach number/Velocity ratios (left, right columns) with three splitter area ratios (rows) using convergent nozzle. 

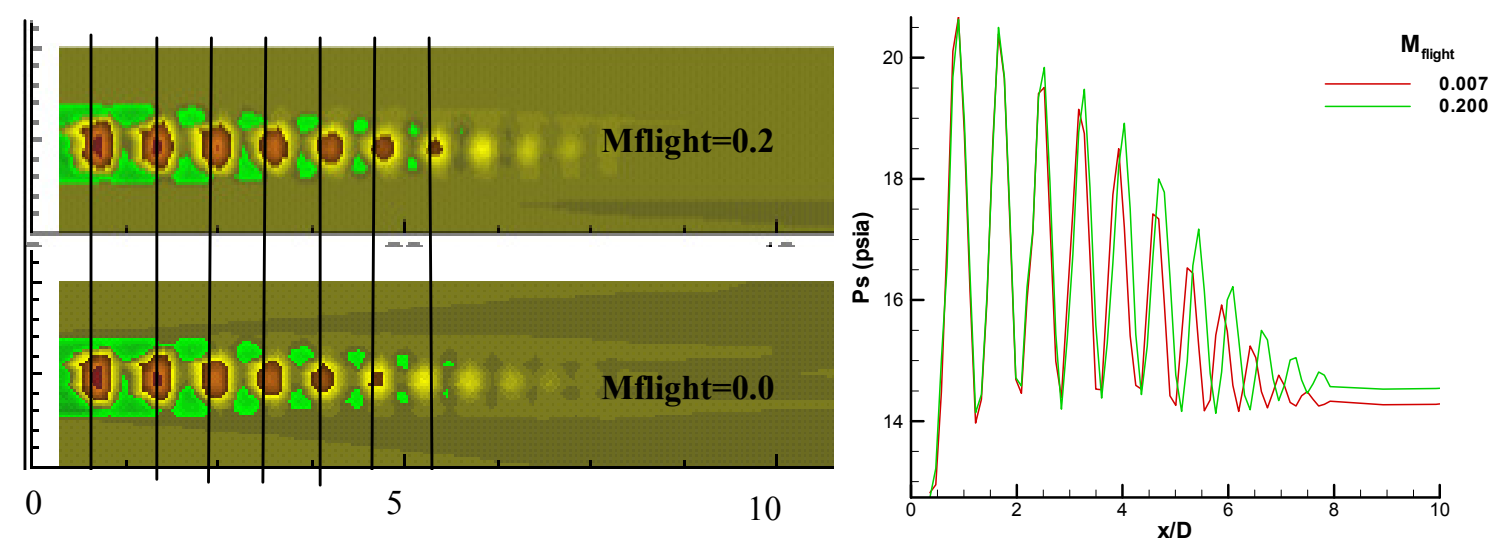

Figure 5.-Pstat for $M=1.2$ shocked jet from convergent nozzle with area ratio 0.2 splitter, operating at velocity ratio 0.60 , in the presence of two different flight Mach numbers: static and $M_{f}=0.2$. Vertical lines have been drawn on contour plots to highlight slight variations in shock cell spacing and strength at the end of the potential core. Same color scale as Figure 4.

\section{Orientation to Acoustic Datasets}

In principle, the acoustic dataset acquired during our tests has variations in three key parameters: Mach number $M$, velocity ratio $U_{b} / U_{c}$, and splitter area ratio. Analysis of the acoustic data is based on the idea of keeping the shock cell structure fixed by holding the Mach number constant and varying the other two parameters one at a time.

To orient the reader, Figure 6 compares carpet plots of the spectral directivity measured from an ideally expanded nozzle and from a convergent nozzle. The former is almost completely dominated by jet mixing noise at low frequencies and aft angles, while the latter has the frequency-shifting ridge of the BBSN across the broadside angles with frequencies just higher than the peak jet mixing noise at those angles. The best view of the BBSN is then to look at spectra at angles in the upstream arc, typically $60^{\circ}$ and $90^{\circ}$. It is also worth a birds-eye look at one of the common changes seen in the BBSN with changes in the internal shear layer. Figure 7 shows the spectral directivity of two convergent nozzles, identical except for a change in the area ratio between the hot core and the cold bypass streams. Focusing on the BBSN ridge, note how the peak of the BBSN shifts from far forward angles to more broadside, peaking just aft of $90^{\circ}$. Therefore it is important to look at more than just one angle to see the impact of changes being made, as will be done in the presentation of acoustic data below.

One other aspect of the spectra can be distracting: after having atmospheric attenuation removed, the spectra often have a sharp upturn at their highest frequencies. This phenomena, also noted in Reference 2, is not an artifact of inadequate dynamic range, of improper application of atmospheric attenuation correction or microphone calibration: subsonic jet noise spectra acquired during the same test do not exhibit this anomaly. A strong clue to the problem was given by comparing measurements acquired simultaneously at two different distances. The subsonic spectra acquired at both locations fell on top of one another when transformed to a common distance, but the supersonic jet spectra showed varying degrees of this high frequency upturn. It is believed that nonlinear propagation, which does not scale with Strouhal scaling, was pumping additional energy into the high frequencies over the distance to the microphones and hence could not be accounted for by linear spherical spreading considerations. 

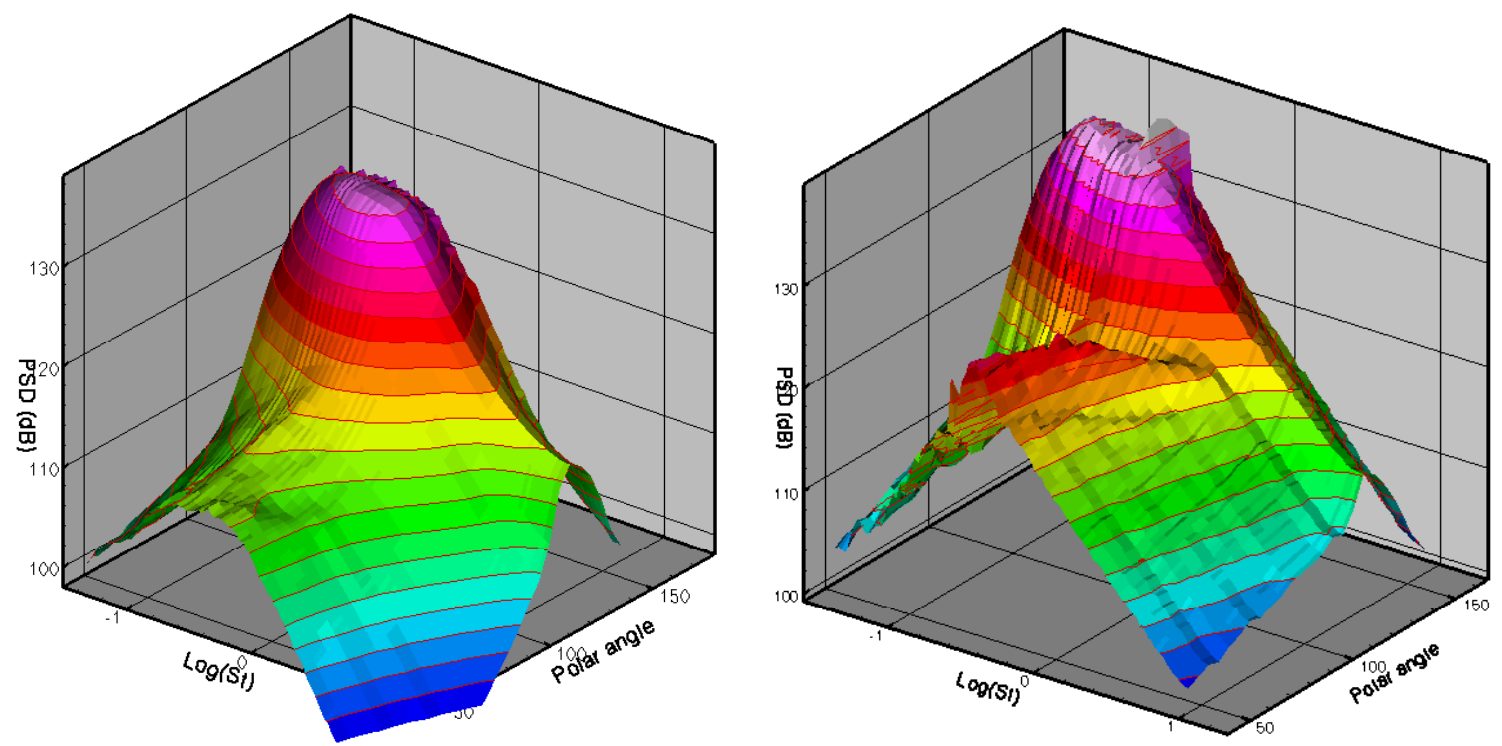

Figure 6.-Power spectral density directivity for ideally expanded (left) and convergent nozzle (right) with splitter area ratio 0.2 , operating at fully expanded $M=1.5, U_{b} / U_{c}=0.58$.
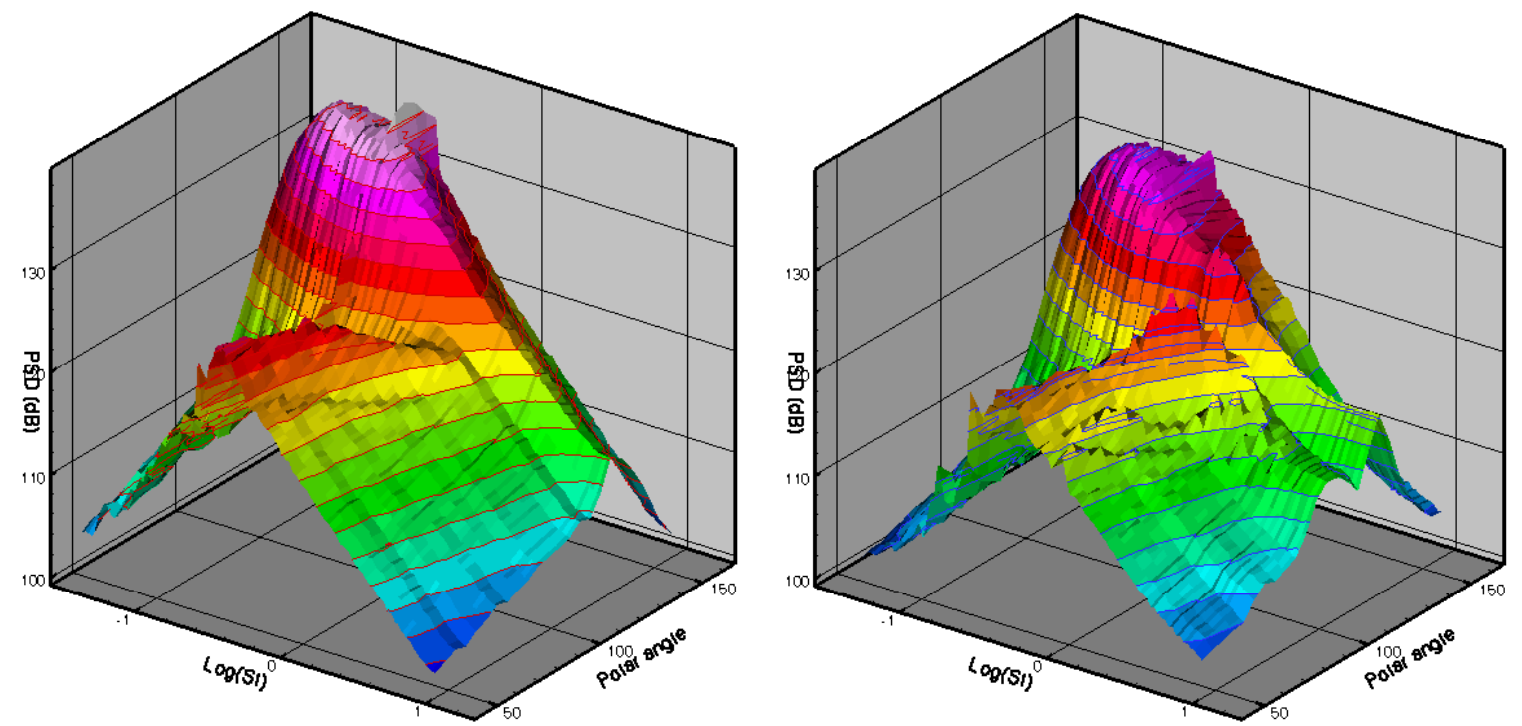

Figure 7.-Power spectral density directivity for convergent nozzle with splitter area ratio = 0.2 (left) and 2.0 (right) operating at $M=1.5, U_{b} / U_{c}=0.58$.

\section{Impact of Temperature on Broadband Shock Noise From Single-Stream Jets}

As has been noted previously (Refs. 1 and 2), broadband shock noise in a single-stream jet has relatively little dependence on temperature for a given Mach number. Viswanathan (Ref. 2) demonstrated that the broadband shock noise is not entirely independent of temperature, at least in its scaling with Mach number, especially as one considers all observation angles. But for a given Mach number $M$ one expects that the BBSN will be fixed as the jet mixing noise varies with jet temperature, hence velocity. This is shown in Figure 8 where jet spectral density curves of a $M=1.5$ jet (nozzle C4.5) heated to total temperature ratios up to 2.6 are plotted for observation angles $60^{\circ}$ and $90^{\circ}$. In each plot, thin smooth lines give the estimated jet mixing noise as a visual aid in picking out the BBSN. These spectra were created using an empirically derived hot subsonic jet noise model based on the fully mixed velocity and 

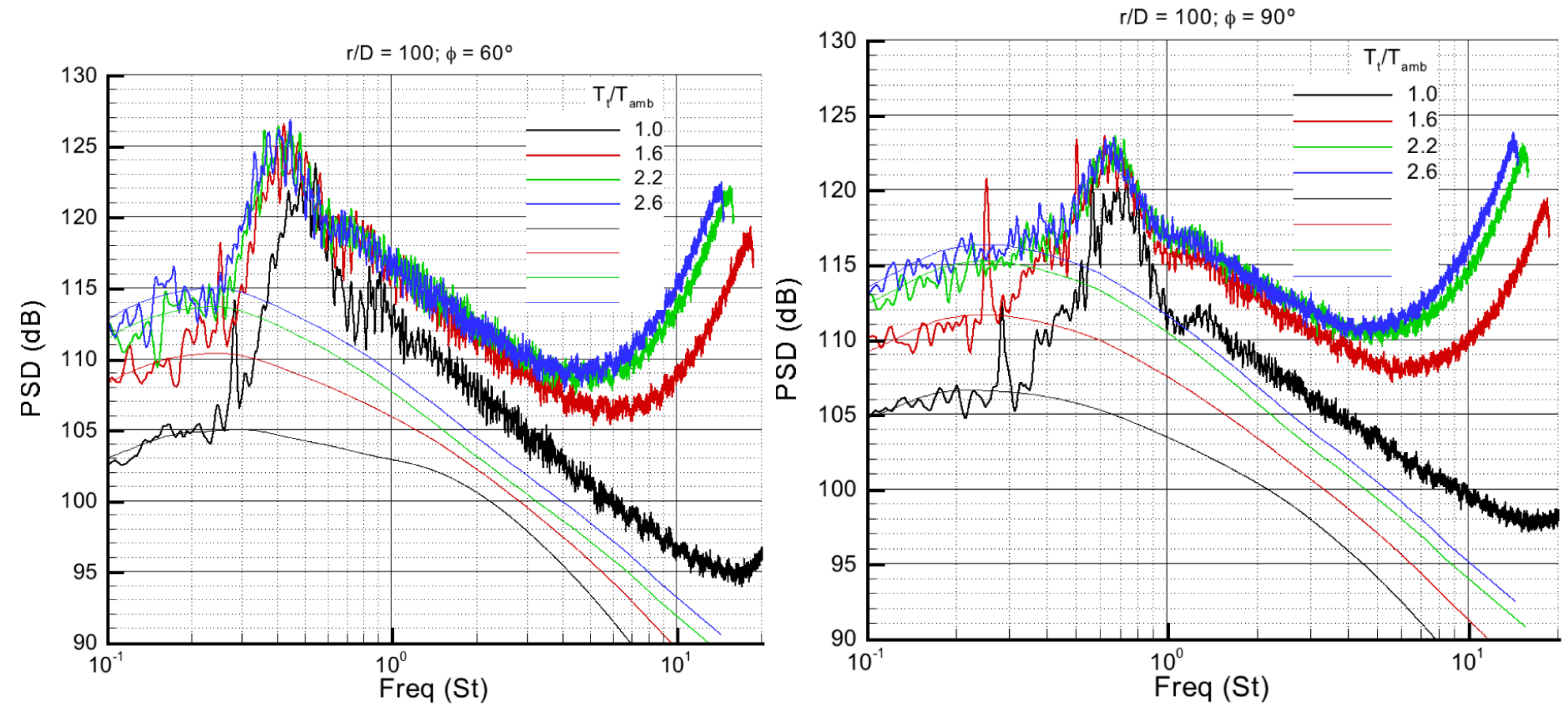

Figure 8.-Power Spectral Density of shocked jet noise at $60^{\circ}$ (left) and $90^{\circ}$ (right) for $M=1.5$ single-stream jets of total temperature ratios $1.0,1.6,2.2$, and 2.6. Curves on each plot are for velocity ratios $U_{b} / U_{c}=1.0,0.66$, 0.6 (top to bottom). Smooth curves are estimates of mixing noise.
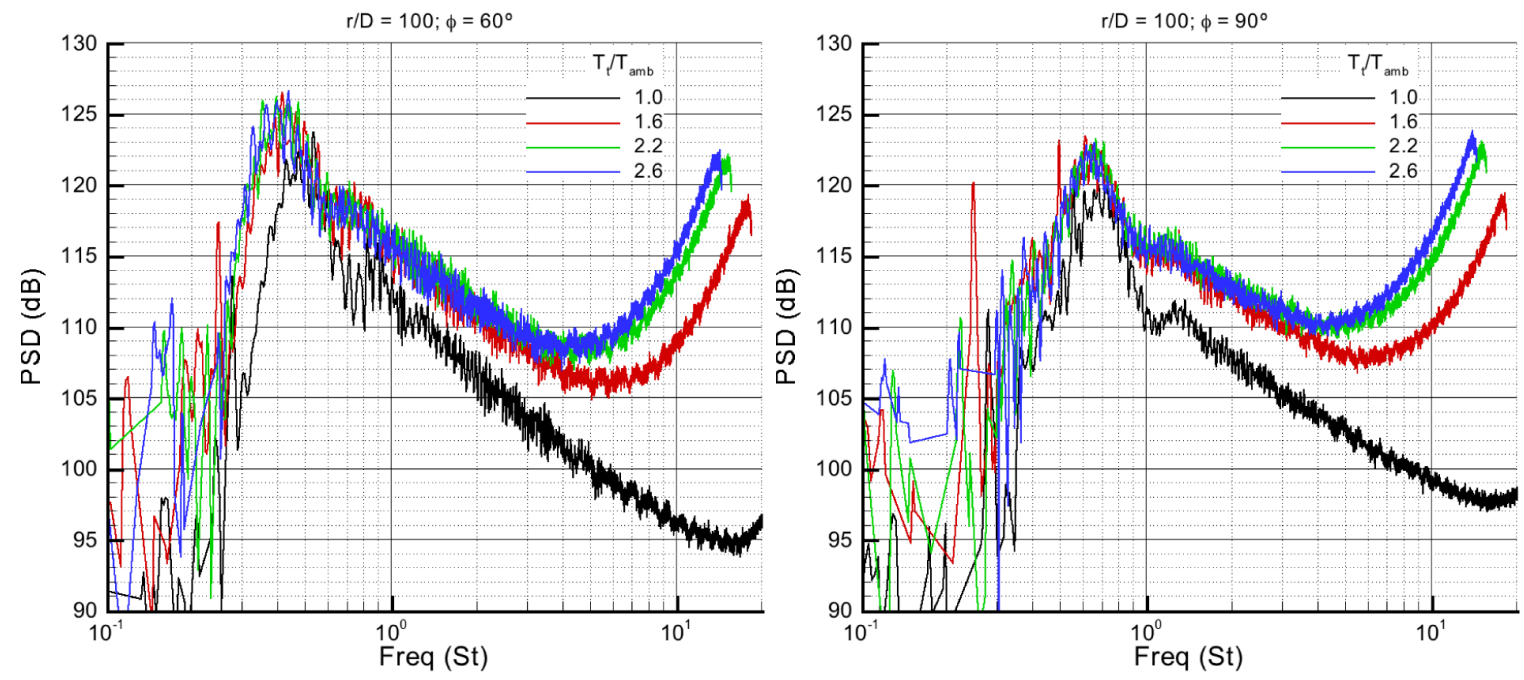

Figure 9.-Power Spectral Density of BBSN at $60^{\circ}$ (left) and $90^{\circ}$ (right). BBSN component derived from removal of jet mixing noise estimates shown in previous figure.

temperature (derived in a fashion similar to that of (Ref. 2) and matched in power for Strouhal numbers below 0.2. Figure 9 shows the estimates of the BBSN in as found by power subtraction of the jet mixing noise estimates from the total measured noise.

In the plots of Figure 9, the BBSN of the hot jets collapsed within $\pm 1 \mathrm{~dB}$ over most of the frequency range $(\mathrm{St}<4)$, but the cold jet did not collapse. While it is possible that the empirical jet mixing noise model used is to blame, previous explorations of ideally mixed jets does not show such a strong change in high frequency mixing noise as would be required to bring down the hot BBSN to the level of the cold jet. Also, there was also a bit of a frequency shift in the peak BBSN at $60^{\circ}$ from the cold jet to the hot jets. However, the alignment of the peaks with different temperature ratios was fairly close compared to the changes observed in the dual stream BBSN, to be considered next. 


\section{Impact of Splitter Area Ratio on Broadband Shock Noise}

In the first comparison of dual-stream acoustic datasets, the velocity ratio $U_{b} / U_{c}$ is held fixed by keeping the core stream temperature constant while varying the splitter area ratio. These comparisons are shown in Figure 10 for $M=1.2$ and in Figure 11 for $M=1.5$. The first row of plots in Figure 10 show spectra at $60^{\circ}$ and $90^{\circ}$ for the case of velocity ratio $U_{b} / U_{c}=1$, where all splitter geometries should produce the same sound since the two streams are identical cold flow. The subsequent rows in each figure present spectra for different velocity ratios at these two observer angles. In each plot, thin smooth lines give the estimated jet mixing noise as a visual aid in picking out the BBSN. Unlike the previous case of single-stream jets, direct subtraction of the mixing noise was not trusted since the empirical jet mixing noise model only fits the spectra of single-stream jets and does not necessarily match the high frequency portion of noise spectra from dual-stream jets.

At $M=1.2$ (Fig. 10), the plots of the first row shows what amounts to very good repeatability of the cold flow case for different model changes. The next two plots show how the change in geometry for the two velocity ratios resulted first in different jet mixing noise and second in a substantial increase in the peak of the BBSN at $90^{\circ}$. The directivity of the BBSN is modified by the change in the internal shear layer geometry. Note that in the case of $U_{b} / U_{c}=0.69$ there was substantial screech that was missing in the $U_{b} / U_{c}=0.6$ case. The latter case was apparently hot enough that the feedback wavelengths had frequencies that did not match those of the jet column instability, and hence did not support screech. However, from the very slight differences in BBSN between the two velocity ratio cases it appears that screech did not have a very strong impact on the BBSN.

At $M=1.5$ (Fig. 11), the impact of the internal shear layer geometry was similar. The velocity ratio of 0.83 apparently did not produce enough of an internal shear layer to substantially change the spectra in the first row of plots. As the core flow was heated further, the peak BBSN was reduced and shifted to higher frequencies with increases in splitter area ratio. This change is not dramatic: the difference in peak amplitude was only $2 \mathrm{~dB}$ and the frequency shift was roughly 25 percent at its greatest (velocity ratio 0.58 ). A keen eye notes that there is also a shift in the screech tone of approximately the same amount in the case of $U_{b} / U_{c}=0.68$; a check of the recorded flow conditions confirms that the pressure ratios and temperature ratios were all within less than 0.5 percent of each other and that the frequency shift is not an error in setting flow conditions.

\section{Impact of Velocity Ratio $U_{b} / U_{c}$ on BBSN}

In another comparison of the dual-stream datasets, this time splitter area ratio was held fixed along with Mach number $M$, and the core temperature and hence velocity ratio $U_{b} / U_{c}$ was varied. We say velocity ratio varies instead of temperature ratio because of the relative indifference of the peak BBSN with temperature, demonstrated previously. Each row of plots in Figures 12 and 13 corresponds to a different splitter area ratio. Note that each plot includes the $U_{b} / U_{c}=1$ flow condition (both streams cold) to see the impact of the internal shear layer. In the first row of plots in Figure $12(M=1.2)$, increasing the core temperature strongly impacted the jet mixing noise as the core stream has 80 percent of the flow area at the splitter. The BBSN was not heavily influenced at $60^{\circ}$, but was strongly impacted at $90^{\circ}$, increasing both the peak frequency and amplitude with the increase in core velocity/temperature. For the nozzles with splitter area ratios 1.0 and 2.0 the peak BBSN increased by over $5 \mathrm{~dB}$.

In Figure $13(M=1.5)$ four velocity ratios are presented in each plot: $1.0,0.83,0.68$, and 0.58 . Here the changes observed with increasing core velocity/temperature were very similar to $M=1.2$, but the addition of another velocity ratio highlights an interesting jump in the behavior at high frequencies. These plots show that the BBSN spectra for $U_{b} / U_{c}=1.0$ and 0.83 were very similar, but very different from those of $U_{b} / U_{c}=0.68$ and 0.58 . The change in BBSN happens abruptly for a velocity ratio between 0.83 and 0.68 , signaling a dramatic change in the source mechanism at a critical velocity ratio. Quick checks of convective Mach numbers of these flows did not explain the jump - for all flow the outer shear layer remained convectively supersonic and inner shear layer remained convectively subsonic. Further, the 

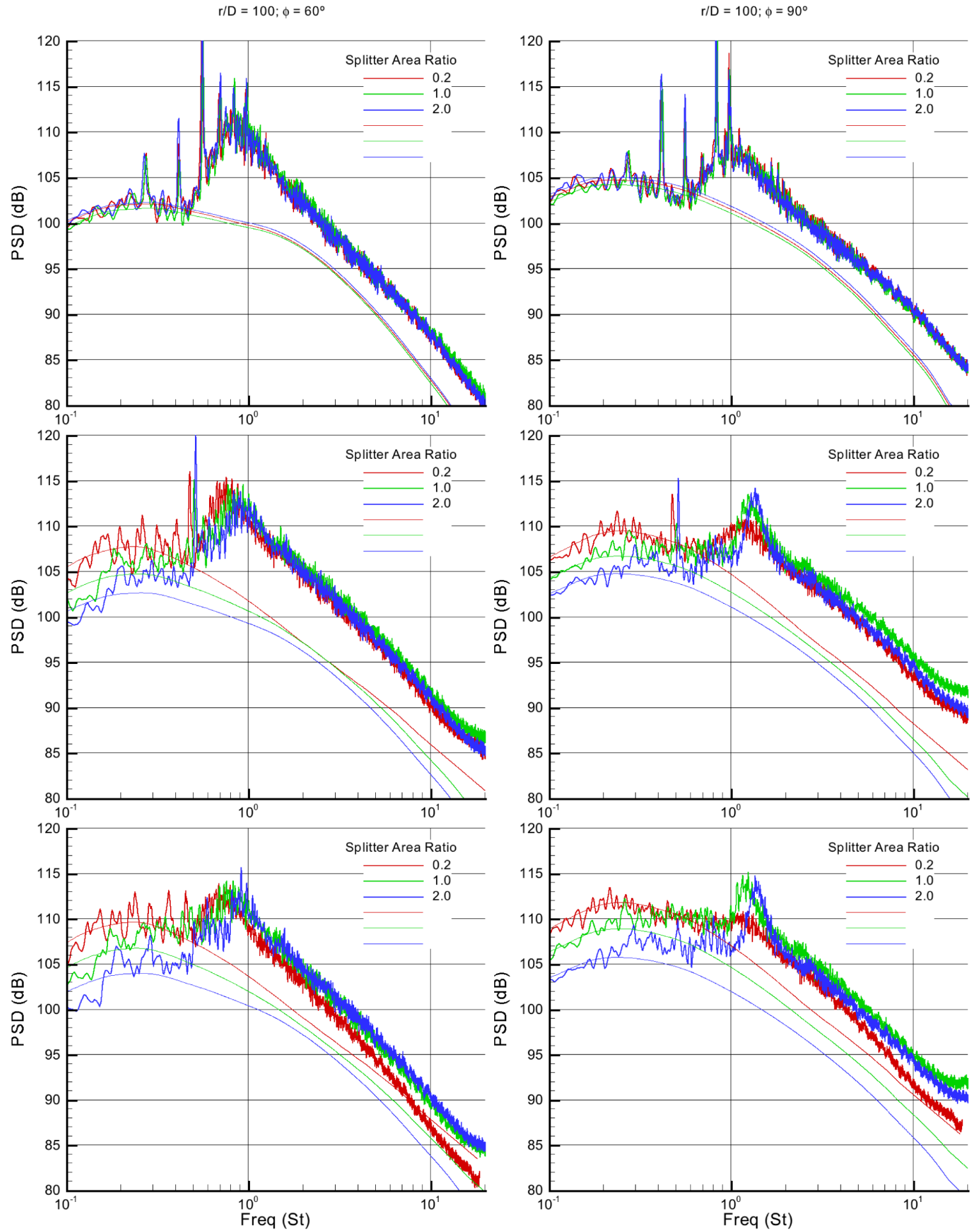

Figure 10.-Power Spectral Density of shocked jet noise at $60^{\circ}$ (left) and $90^{\circ}$ (right) for $M=1.2$ at velocity ratios $U_{b} / U_{c}=1.0,0.66$, and 0.6 (top to bottom). Smooth curves are estimates of mixing noise. 

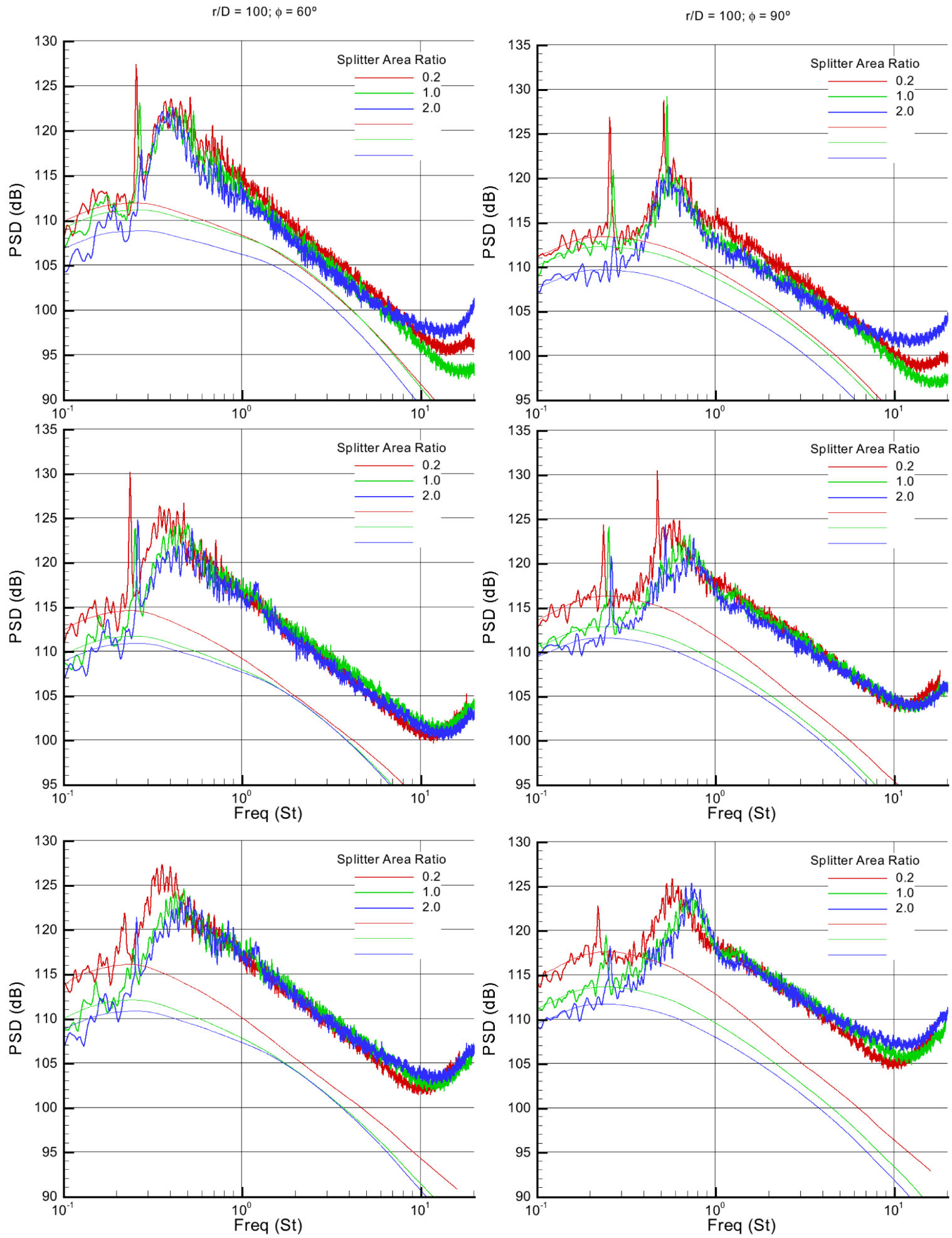

Figure 11.-Power Spectral Density of shocked jet noise at $60^{\circ}$ (left) and $90^{\circ}$ (right) for $M=1.5$ at velocity ratios $U_{b} / U_{c}=0.83,0.69$, and 0.58 (top to bottom). Smooth curves are estimates of mixing noise. 

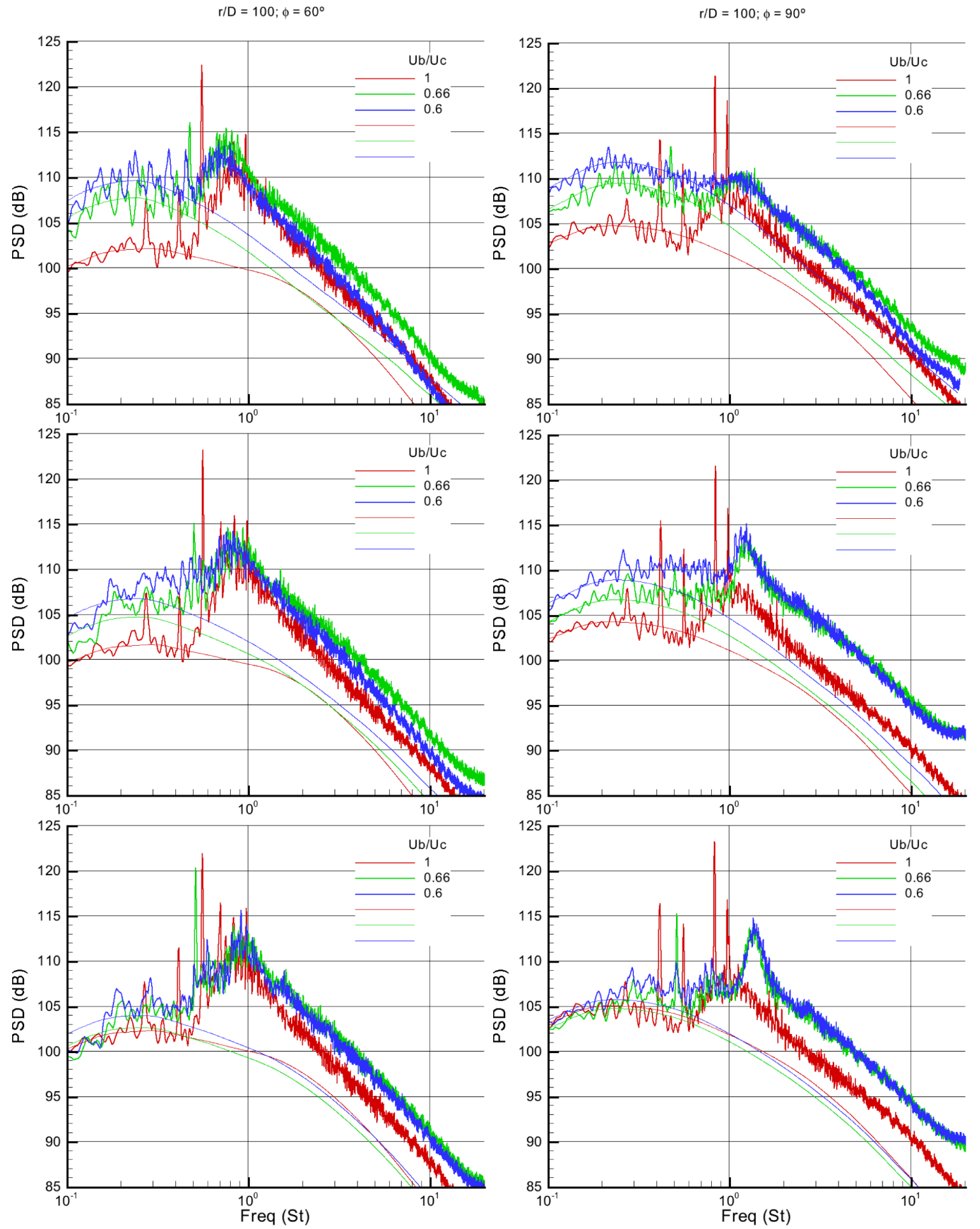

Figure 12.-Power Spectral Density of shocked jet noise at $60^{\circ}$ (left) and $90^{\circ}$ (right) for $M=1.2$ from nozzles with splitter area ratios $0.2,1.0$, and 2.0. Curves on each plot are for velocity ratios $U_{b} / U_{c}=1.0,0.66$, and 0.6 (top to bottom). Smooth curves are estimates of mixing noise. 

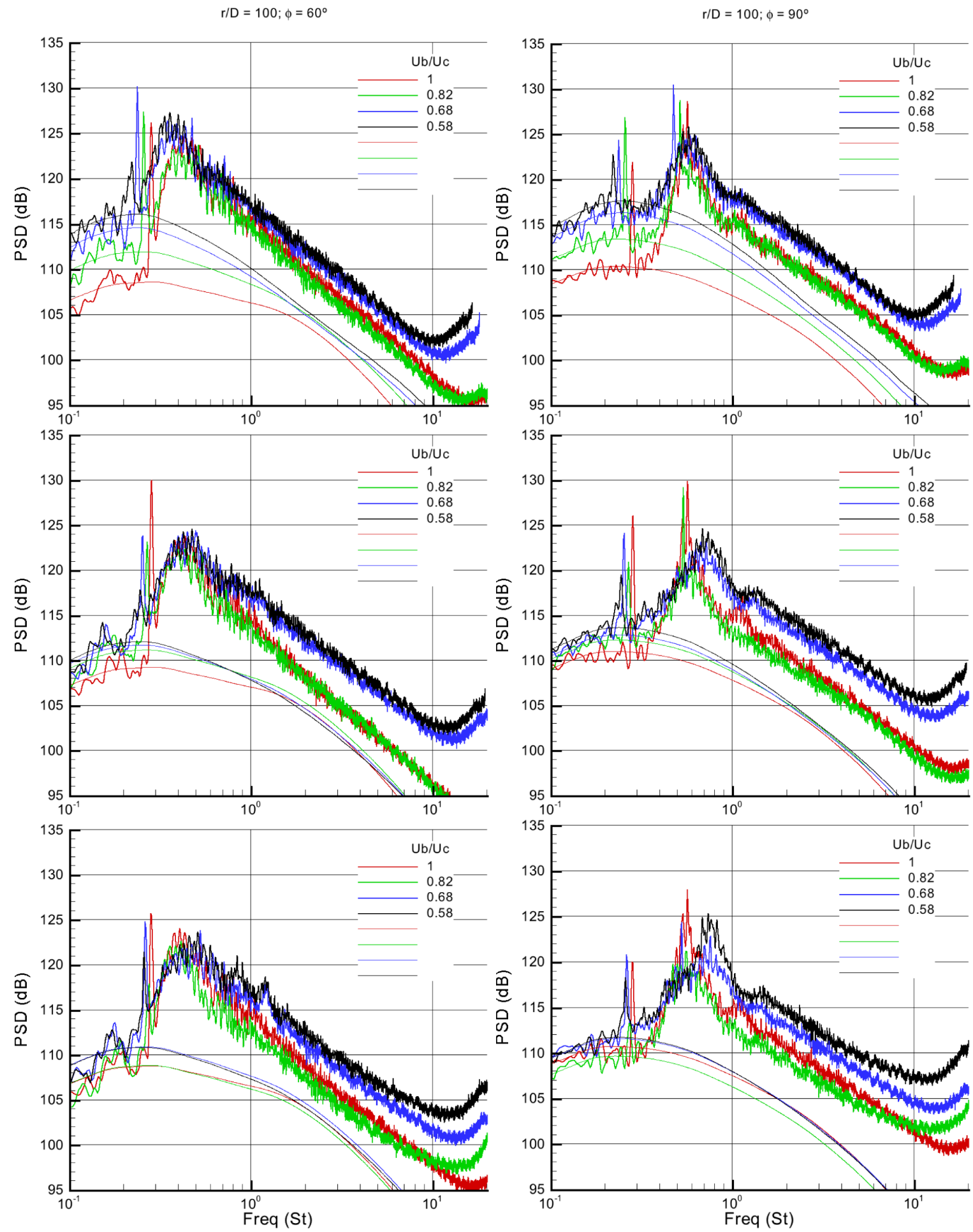

Figure 13.-Power Spectral Density of shocked jet noise at $60^{\circ}$ (left) and $90^{\circ}$ (right) for $M=1.5$ from nozzles with splitter area ratios $0.2,1.0$, and 2.0 (top to bottom). Curves on each plot are for velocity ratios $U_{b} / U_{c}=1.0,0.82$, 0.68 , and 0.58 . Smooth curves are estimates of mixing noise. 
convective Mach number for the merged shear layer was likewise always convectively supersonic. The current best guess, guided by the behavior of BBSN observed in heated single-stream jets, is that this discontinuity corresponds to the one observed between the purely cold jet and the heated jets, starting with temperature ratio 1.6.

In closing this section, we note that Viswanathan (Ref. 2) found some discontinuity in the scaling of BBSN frequency scaling with Mach number, and concluded the same as we do here - there is more to BBSN than can be captured in simple scaling laws.

\section{Impact of Forward Flight on BBSN}

Up until now we have been considering the impact of velocity ratio between core and bypass streams on the BBSN. Now consider the impact of velocity ratio of the external shear layer. This was modified in our tests by changes in the flight speed, here denoted by the flight Mach, $M_{f}$. The flight effect on jet mixing noise is well understood, as is the impact of forward flight on the BBSN of single stream jets (Ref. 7). Forward flight causes a very slight stretch in the shock cell pattern, as noted in the plume plots above. It also reduces the velocity gradient, and hence turbulence, of the jet shear layer. Correspondingly, the impact on the noise is expected to be a very slight frequency shift and perhaps a slight reduction in amplitude with forward flight. This was the result obtained in previous work with a single-stream jet flow (Ref. 6).

As can be seen in the plots below, the result was a little more complicated, but entirely in line with previous studies. Both figures contain power spectral density of the noise from a $M=1.2$ jet at different forward flight speeds. Each figure has three plots corresponding to observer angles of $60^{\circ}, 90^{\circ}$, and $120^{\circ}$. Data in Figure 14 come from a nozzle with a 0.2 area ratio splitter, while data in Figure 15 come from a nozzle with splitter of area ratio 3.0. Both nozzle systems were running with a hot core stream, producing a velocity ratio of 0.66 . In both figures, at all angles, low frequency mixing noise was reduced with increased forward flight speed, as expected. For instance, the peak mixing noise reduction at $120^{\circ}$ matches with a relative velocity exponent of roughly 6 -very close to values found for other jets (Ref. 8). At forward angles, increasing the flight speed increased the peak BBSN by several dB. At $90^{\circ}$, the BBSN was relatively insensitive to the flight speed. At $120^{\circ}$ the BBSN was mostly covered by the mixing noise, but made its presence known by staying approximately the same while the mixing noise reduced with increased flight speed. This is easier to see in Figure 15 where the high bypass ratio kept the jet mixing noise lower while the BBSN was largely unaffected by the change in bypass ratio. These two figures span the range of nearly fully cold jet (with splitter area ratio 3 ) to nearly fully hot jet (with splitter area ratio 0.2 ) but in keeping with the findings of the previous section, the BBSN is very nearly the same in both nozzle systems and it is the differences in jet mixing noise that create most of the differences between figures.
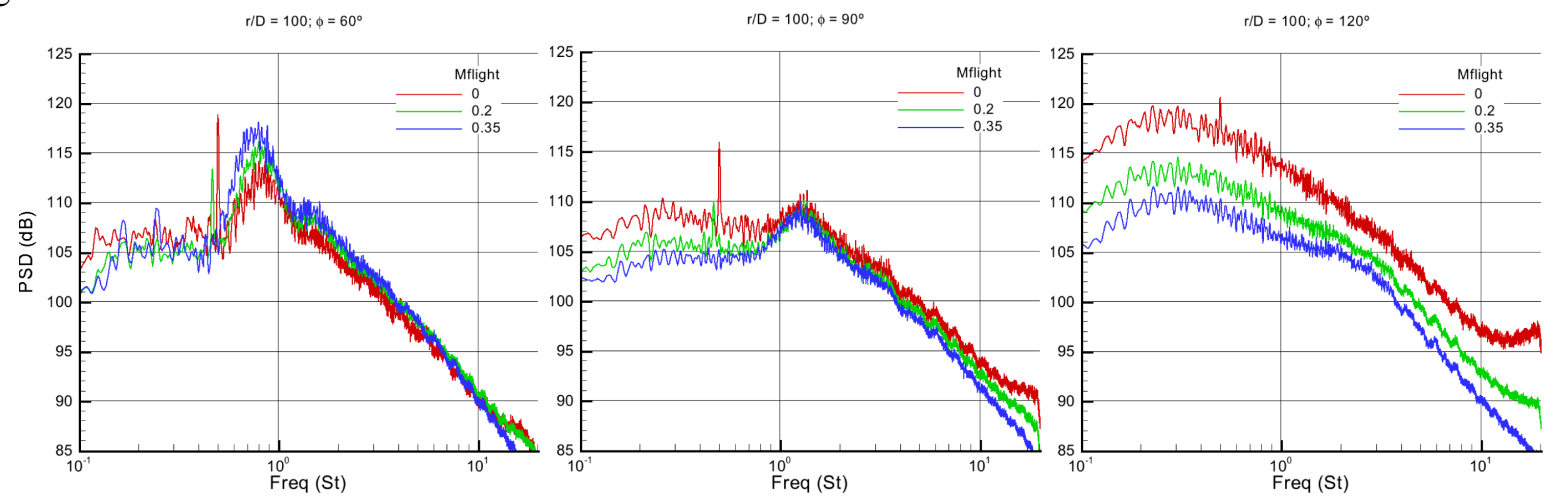

Figure 14.-Power Spectral Density of sound at $60^{\circ}$ (left), $90^{\circ}$ (middle) and $120^{\circ}$ (right) for $M=1.2$, velocity ratio $U_{b} / U_{c}=0.66$ at splitter area ratio 0.2. Curves on each plot are for three different flight Mach numbers, $0.0,0.2$, and 0.35 . 

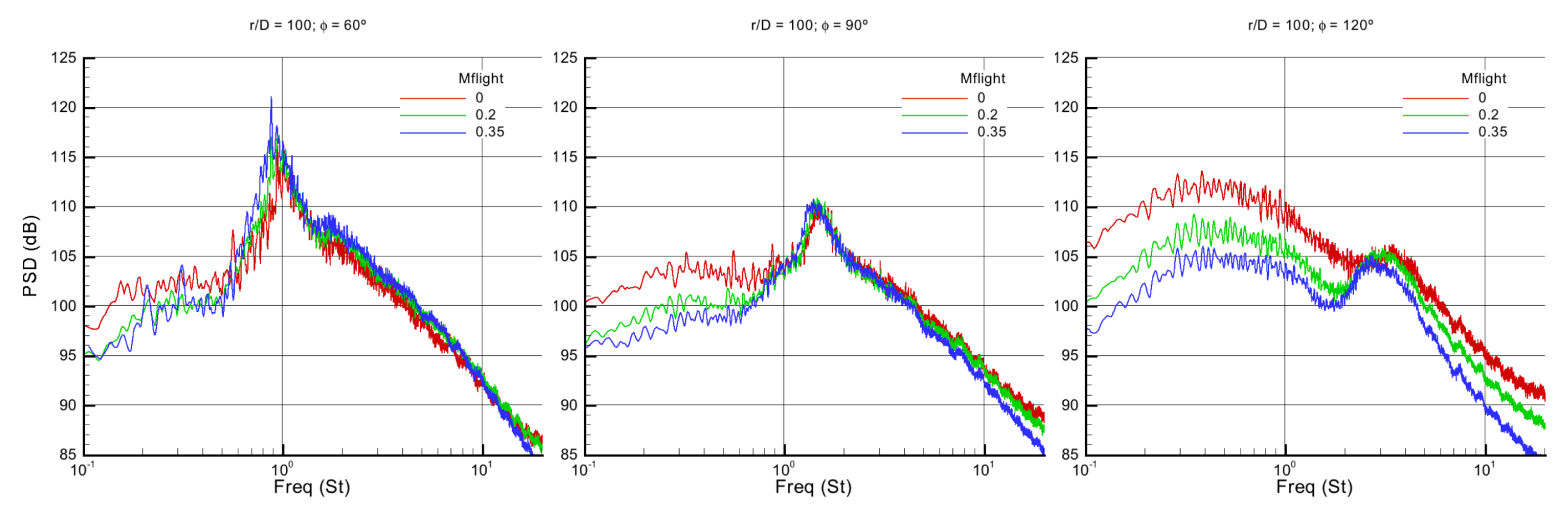

Figure 15.-Power Spectral Density of sound at $60^{\circ}$ (left), $90^{\circ}$ (middle), and $120^{\circ}$ (right) for $M=1.2$, velocity ratio $U_{b} / U_{c}=0.66$ at splitter area ratio 3.0. Curves on each plot are for three different flight Mach numbers, 0.0, 0.2, and 0.35 .

\section{Discussion}

Overall we see that broadband shock noise was affected by changes to the internal shear layer of the dual-stream jet, although not as much as the jet mixing noise. The main change was in the peak frequency of the BBSN and its directivity. With increasing fully mixed jet velocity the peak frequency of the BBSN shifts to higher frequencies, although it is not necessarily a smooth shift with velocity. The abrupt change seen with small changes in mixed velocity may be linked to the observed changes seen with small amounts of heating in the single-stream jet. Since the change in velocity was accomplished via changes in temperature, the change may be better explained through the temperature or density effect, although the usual mechanism of broadband shock noise is usually given by kinematic arguments and previous investigations have shown BBSN to be relatively independent of temperature for a given Mach number. Presumably the change in directivity would also fall out of proper application of current theories, such as that of Tam (Ref. 9), although this has not been done.

It was something of a disappointment that no evidence could be found for an independent source of broadband shock noise associated with the inner shear layer. Either this turbulence was too correlated with that of the outer shear layer as it traversed the shocks, it was too weak compared with the outer shear layer, or did not span enough shock cells before merging with the outer shear layer to register as an independent, additive noise source in the far-field spectra. The changes observed in the far-field spectra with changes in the internal shear layer were modifications of the spectra, not additive effects.

\section{Summary}

Both flow and far-field acoustic measurements have been made on internally mixed exhaust systems running at supersonic jet flow conditions. The exhaust systems had different internal area ratios and used both convergent and convergent-divergent nozzles. Analysis was made by holding the Mach number of the flow constant which kept the shock structure of the jet fixed. The flow measurements showed that the common shock structure of the plume was barely affected by the changes in area ratio or velocity ratio for a given Mach number. The noise was more significantly affected. Of leading order was the expected change in jet mixing noise with changes in the fully mixed velocity. Of more interest here was the change in the peak frequency and directivity of the broadband shock noise with changes in the internal shear layer. Also demonstrated was the impact of screech on jet mixing noise and broadband shock noise as screech was eliminated first by physically perturbing the lip of the convergent nozzle and then by elevating the jet temperature. Finally, the effect of forward flight was documented in these mixed stream jets and found to be of small impact on the broadband shock noise while strongly changing the jet mixing noise. This combination could lead to less than expected noise reduction in flight for jets with weak shocks. 


\section{References}

1. Tanna, H.K., “An Experimental Study of Jet Noise, Part II: Shock Associated Noise,” J. Sound and Vibration, 50(3), pp. 429-444, 1977.

2. Viswanathan, K., Alkislar, M., and Czech, M., "Characteristics of the Shock Noise Component of Jet Noise," AIAA Paper 2008-2835, 2008.

3. Tam, C.K.W., and Tanna, H.K., "Shock Associated Noise of Supersonic Jets From ConvergentDivergent Nozzles," J. Sound and Vibration, 81(3), pp. 337-358, 1982.

4. Shields, F.D. and Bass, H.E., "Atmospheric Absorption of High Frequency Noise and Application to Fractional-Octave Band," NASA-CR 2760, (1977).

5. Bridges, J. and Wernet, M.P., "Turbulence Associated With Broadband Shock Noise in Hot Jets," AIAA Paper 2008-2834 (2008).

6. Norum, T.D. and Shearin, J.G., "Shock Structure and Noise of Supersonic Jets in Simulated Flight to Mach 0.4," NASA Technical Paper 2785 (1988).

7. Tam, C.K.W., "Broadband Shock-Asociated Noise From Supersonic Jets in Flight," J. Sound and Vibration 151, pp. 131-147 (1991).

8. Nesbitt, E. and Young, R., "Forward Flight Effects on Chevron Noise Reduction," AIAA Paper 20083065 (2008).

9. Tam, C.K.W., "Stochastic Model Theory of Broadband Shock Associated Noise From Supersonic Jets," J. Sound and Vibration 116, 265-302 (1987). 


\begin{tabular}{|c|c|c|}
\hline \multicolumn{2}{|c|}{ REPORT DOCUMENTATION PAGE } & $\begin{array}{c}\text { Form Approved } \\
\text { OMB No. 0704-0188 }\end{array}$ \\
\hline \multicolumn{3}{|c|}{ 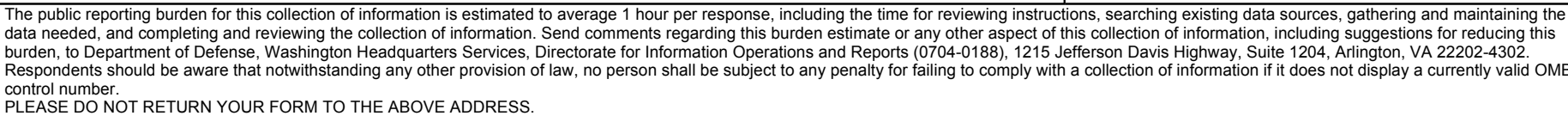 } \\
\hline $\begin{array}{l}\text { 1. REPORT DATE (DD-MM-YYYY) } \\
01-11-2009\end{array}$ & $\begin{array}{l}\text { 2. REPORT TYPE } \\
\text { Technical Memorandum }\end{array}$ & 3. DATES COVERED (From - To) \\
\hline \multirow{3}{*}{\multicolumn{2}{|c|}{$\begin{array}{l}\text { 4. TITLE AND SUBTITLE } \\
\text { Broadband Shock Noise in Internally-Mixed Dual-Stream Jets }\end{array}$}} & 5a. CONTRACT NUMBER \\
\hline & & 5b. GRANT NUMBER \\
\hline & & 5c. PROGRAM ELEMENT NUMBER \\
\hline \multirow{3}{*}{\multicolumn{2}{|c|}{$\begin{array}{l}\text { 6. AUTHOR(S) } \\
\text { Bridges, James, E. }\end{array}$}} & 5d. PROJECT NUMBER \\
\hline & & 5e. TASK NUMBER \\
\hline & & $\begin{array}{l}\text { 5f. WORK UNIT NUMBER } \\
\text { WBS 984754.02.07.03.17.03 }\end{array}$ \\
\hline \multicolumn{2}{|c|}{$\begin{array}{l}\text { 7. PERFORMING ORGANIZATION NAME(S) AND ADDRESS(ES) } \\
\text { National Aeronautics and Space Administration } \\
\text { John H. Glenn Research Center at Lewis Field } \\
\text { Cleveland, Ohio 44135-3191 }\end{array}$} & $\begin{array}{l}\text { 8. PERFORMING ORGANIZATION } \\
\text { REPORT NUMBER } \\
\text { E-17079 }\end{array}$ \\
\hline \multirow{2}{*}{\multicolumn{2}{|c|}{$\begin{array}{l}\text { 9. SPONSORING/MONITORING AGENCY NAME(S) AND ADDRESS(ES) } \\
\text { National Aeronautics and Space Administration } \\
\text { Washington, DC 20546-0001 }\end{array}$}} & $\begin{array}{l}\text { 10. SPONSORING/MONITOR'S } \\
\text { ACRONYM(S) } \\
\text { NASA; AIAA }\end{array}$ \\
\hline & & $\begin{array}{l}\text { 11. SPONSORING/MONITORING } \\
\text { REPORT NUMBER } \\
\text { NASA/TM-2009-215817; AIAA-2009- } \\
3210\end{array}$ \\
\hline \multicolumn{3}{|c|}{$\begin{array}{l}\text { 12. DISTRIBUTION/AVAILABILITY STATEMENT } \\
\text { Unclassified-Unlimited } \\
\text { Subject Category: } 71 \\
\text { Available electronically at http://gltrs.grc.nasa.gov } \\
\text { This publication is available from the NASA Center for AeroSpace Information, 443-757-5802 }\end{array}$} \\
\hline
\end{tabular}

\section{SUPPLEMENTARY NOTES}

\section{ABSTRACT}

Broadband shock noise (BBSN) has been studied in some detail in single-flow jets and recently in dual-stream jets with separate flow exhaust systems. Shock noise is of great concern in these latter cases because of the noise created for the aircraft cabin by the underexpanded nozzle flow at cruise. Another case where shock noise is of concern is in the case of future supersonic aircraft that are expected to have bypass ratios small enough to justify internally mixed exhaust systems, and whose mission will push cycles to the point of imperfectly expanded flows. Dual-stream jets with internally mixed plume have some simplifying aspects relative to the separate flow jets, having a single shock structure given by the common nozzle pressure. This is used to separate the contribution of the turbulent shear layer to the broadband shock noise. Shock structure is held constant while the geometry and strength of the inner and merged shear layers are varying by changing splitter area ratio and core stream temperature. Flow and noise measurements are presented which document the efforts at separating the contribution of the inner shear layer to the broadband shock noise.

\section{SUBJECT TERMS}

Aerodynamic noise; Aeroacoustics; Jet noise; Convergent-divergent nozzles; Broadband; Shock waves; Spectra; Temperature ratio; Shear layers; Dual-stream

\begin{tabular}{|c|c|c|c|c|c|}
\hline \multicolumn{3}{|c|}{ 16. SECURITY CLASSIFICATION OF: } & \multirow{2}{*}{$\begin{array}{l}\text { 17. LIMITATION OF } \\
\text { ABSTRACT } \\
\text { UU }\end{array}$} & \multirow{2}{*}{$\begin{array}{l}\text { 18. NUMBER } \\
\text { OF } \\
\text { PAGES } \\
23\end{array}$} & \multirow{2}{*}{$\begin{array}{l}\text { 19a. NAME OF RESPONSIBLE PERSON } \\
\text { STI Help Desk (email:help@ } \text { sti.nasa.gov) } \\
\text { 19b. TELEPHONE NUMBER (include area code) } \\
\text { 443-757-5802 }\end{array}$} \\
\hline $\begin{array}{l}\text { a. REPORT } \\
U\end{array}$ & $\begin{array}{l}\text { b. ABSTRACT } \\
\mathrm{U}\end{array}$ & $\begin{array}{l}\text { c. THIS } \\
\text { PAGE } \\
\text { U }\end{array}$ & & & \\
\hline
\end{tabular}



